O impeachment de 2016 no contexto das crises presidenciais da América Latina (Entrevista com Aníbal Pérez-Liñan)

[The impeachment in 2016 in the context of the presidential crises in Latin America (Interview with Aníbal PérezLiñan)]

\section{Luãn Chagas}

Universidade do Estado do Rio de Janeiro

[University of Brasilia]

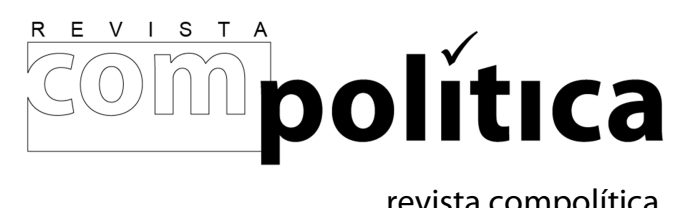

revista compolítica 2016, vol. 6(2) compolitica.org/revista ISSN: 2236-4781 DOI: 10.21878/compolitica.2016.6.2.276 O. Open Access Journal 


\section{O impeachment de 2016 no contexto das crises presidenciais da América Latina (Entrevista com Aníbal Pérez-Liñan)}

Luãn CHAGAS

rgentino radicado na Universidade de Pittsburgh, Estados Unidos, o cientista
político Aníbal Pérez-Liñan é um dos pesquisadores contemporâneos
especializados nas crises presidenciais que resultaram em processos de impeachment e renúncias na América Latina dos anos 1990 a 2000. Os estudos em torno de temas como a democracia, instituições políticas e estado de direito resultaram nos livros Presidential Impeachment and the New Political Instability in Latin America (2007) e Democracies and Dictatorships in Latin America: Emergence, Survival, and Fall (2013), este último em coautoria com Scott Mainwaring. As publicações de Liñan promoveram novos debates e estudos, sobretudo, após os casos de impeachment de Fernando Lugo, em 2012, no Paraguai, e de Dilma Rousseff, em 2016, no Brasil.

Publicado em 2007, o livro Presidential Impeachment and the New Political Instability in Latin America analisa seis casos nos quais o juízo político foi a principal arma para afastar presidentes impopulares e envolvidos em crises. O novo padrão de instabilidade é resultado de quatro fatores, segundo o autor: situação econômica desfavorável, escândalos midiáticos, falta de apoio parlamentar e mobilizações nas ruas contra o presidente. Os casos estudados são Fernando Collor (Brasil, 1992), Carlos Andrés Perez (Venezuela, 1993) Ernesto Samper (Colômbia,1993), que conseguiu a absolvição no Congresso, Abdalá Bucaram (Equador, 1997), Raul Cubas Grau e Gonzalez Macchi (ambos afastados no Paraguai em 1999 e 2002, respectivamente).

Nesta entrevista para a Revista Compolítica, Pérez-Liñan apresenta os argumentos que sustentam a sua tese central. Os diferentes episódios de impeachment na América Latina são indicativos de um novo padrão de instabilidade que emerge a partir dos anos 1990 com a redemocratização. Nove anos após a publicação da obra, as reflexões continuam suscitando debates. As manobras parlamentares no Paraguai e no Brasil, que resultaram em quedas de presidentes eleitos sem crimes de responsabilidades claros, trazem novos 
elementos ao debate. Entre os conceitos recentes que estão sendo trabalhados pelo autor está a capacidade de o grupo governista articular um escudo popular para sensibilizar o Congresso contra a possibilidade de um impeachment; e a presença dos meios de comunicação exercendo papel estratégico para além da divulgação dos escândalos que envolvem o alto escalão presidencial.

Neste âmbito, a entrevista possibilita um aprofundamento nos estudos sobre as crises nos sistemas presidenciais latinos, e suas relações com as fontes de informação alternativas, o uso estratégico das redes sociais pelos atores políticos, o processo de seletividade das informações no jornalismo e os caminhos que a investigação em ciência política deve debater sobre a instituição do impeachment.

Em seu livro, Presidential Impeachment and the New Political Instability in Latin America, as instabilidades políticas do regime presidencialista são objetos para analisar as quedas de presidentes na América Latina nos anos 1990. O que isso representa para as pesquisas em ciência política diante dos conflitos políticos vivenciados na atualidade?

Creio que até os anos 1990 o problema estava centrado na análise sobre a instabilidade do regime e a preocupação fundamental era, em boa medida, pela democracia em si. Essa era uma tradição da ciência política oriunda das investigações sobre os golpes de estado nos anos 1960 e 1970. A partir de 1990, começamos a encontrar padrões que desestabilizam os governos presidenciais sem desestabilizar claramente o regime democrático. Então, a partir deste momento, é necessário repensar os estudos sobre instabilidade para incluir a possibilidade da existência de fatores que desestabilizam o governo sem a necessidade de atingir o regime político. Algo interessante é que algumas condições sociais que desestabilizaram os regimes políticos até os anos 1980 , como a recessão econômica e os protestos sociais, continuam desestabilizando os governos, porém agora num contexto de regime democrático mais resistente, sem a intervenção militar desde 1990. Ou seja, alguns fatores que eram fontes 
de instabilidade no passado continuam sendo fontes de instabilidade no presente.

E como pensar esse contexto de instabilidade diante da polarização social na atualidade e conflitos contínuos entre o Executivo, o Legislativo e o Judiciário?

Existem fatores de instabilidade que ressurgiram na América Latina neste momento. Nos anos 90, um grande período de instabilidade política dos governos foi causado por uma situação econômica muito negativa e porque os governos adotaram políticas neoliberais muito impopulares, como foi o caso de Collor e Carlos Andrés Perez. Isto gerou mobilizações sociais contra o governo e, portanto, instabilidade. Na década entre 2003 e 2013, os governos foram bastante estáveis porque as condições econômicas eram muito favoráveis aos presidentes. Parecia que a questão da instabilidade não era um problema. Porém, com a queda dos preços internacionais das matérias-primas e o ressurgimento da crise econômica em 2012 e 2013, o problema da instabilidade voltou a aparecer. É um tema que, com certeza, temos que pensar.

Quais conceitos-chave são bases para entender as dinâmicas de crise e quais proporcionam os intensos conflitos entre o Legislativo e o Executivo no regime presidencialista?

Acredito que dois conceitos são chaves para entender estes conflitos. O primeiro é o que poderíamos denominar de escudo legislativo do presidente. Esse seria o grupo de membros no Congresso que estão dispostos a respaldar o presidente quando acontecem mobilizações populares pedindo a renúncia do governante. Este escudo legislativo tem a ver com condições institucionais, como sistema de partidos, sistema eleitoral, porém também depende do talento do presidente em negociar com o Congresso e formar coalizões. Quando estudamos os casos de maneira qualitativa, aparece claramente que existem presidentes que possuem mais talento para negociar alianças em Congressos que outros. O segundo conceito-chave, que não está no livro, mas que, com o tempo e as 
pesquisas, se mostrou muito importante, é o que poderíamos chamar de escudo popular do presidente, o outro lado do escudo legislativo. O escudo popular é o setor ou grupo da população que está disposto a respaldar o presidente mesmo em situações que existam escândalos de corrupção ou então que membros do Congresso queiram iniciar um juízo político contra o governo. Este escudo popular do presidente é muito mais forte em períodos que há crescimento econômico e a população está satisfeita com o governo. Por outro lado, o escudo popular se debilita muito em períodos de recessão econômica e inflação.

A votação apertada nos segundos turnos das eleições, tanto de Collor quanto de Dilma e de outros representantes da América Latina, possibilitou a falta de condições para a formação de coalizões no Congresso? Os dados eleitorais, embora apareçam no seu livro, não ganham um destaque específico. Isso também não seria um fator para garantir o amplo apoio durante o governo?

Sim, mas acredito em dois fatores neste sentido. O primeiro é que quando os presidentes ganham com uma vantagem muito pequena, o escudo popular, às vezes, nem sempre, está, pelo menos neste começo de mandato, mais fraco. Em outras palavras, a lealdade do eleitorado para com o presidente é menor. Há menos setores da população dispostos a defender o presidente, caso surjam escândalos ou acusações de corrupção. A lealdade do eleitorado para com o presidente é menor. Porém, é o que também ocorre em casos em que há um segundo turno e o presidente ganha por uma pequena vantagem, sobretudo, naqueles em que o resultado final reverte a votação do primeiro turno. Nestes casos, o presidente tende a ter um apoio mais fragilizado porque o que ocorre é que, mesmo ganhando o segundo turno com a maioria dos votos, acredita que tem um mandato popular forte, porém, no Congresso, a maioria que venceu o primeiro turno é de oposição. Isso então gera uma situação dupla, na qual o presidente crê que possui um escudo popular porque teve a maioria dos votos no segundo turno, porém este escudo popular é fraco e, por sua vez, ainda carece de um escudo legislativo, porque a oposição teve a maioria do congresso no primeiro turno. Em geral, isso é o princípio para criar situações de conflito entre o Legislativo e o Executivo. 
O senhor elenca quatro circunstâncias contextuais que permitiram a possibilidade de impeachment em todos os casos analisados de 1992 a 2002: crise econômica, falta de apoio no legislativo, mobilizações populares e escândalos midiáticos. Em algum ou outro caso eles se acentuam? Como o senhor analisa a atuação midiática para além da investigação e exposição dos escândalos?

Existem duas leituras sobre os meios de comunicação neste contexto e penso que as duas são um tanto ingênuas. A primeira apresenta os meios de comunicação somente como meios independentes que investigam o poder político, no modelo imaginário do Watergate. Pensam os meios como um agente que tem o papel de investigar a corrupção do poder político. Isso, sem dúvida alguma acontece, mas os meios de comunicação são mais do que isso, pois possuem agendas próprias, têm posições editoriais, interesses comerciais etc.

A segunda posição, que também me parece ingênua e está no outro extremo, é a que sustenta que os meios de comunicação são um maquinário hegemônico capaz de manipular a opinião pública contra o governo ou contra os movimentos de esquerda. Essa visão também me parece ingênua pelo que temos visto ao longo do tempo em muitos casos desde a situação política na Venezuela nos anos 90 até a eleição de Donald Trump nos Estados Unidos este ano. Em muitos casos, os mainstream media possuem e defendem uma posição e a reação popular é oposta a essa postura. Isso aumenta hoje em dia, sobretudo, pelas fontes alternativas de informação que a população consome.

Então, creio que para entender esses processos, temos que pensar os meios de comunicação como atores estratégicos, que possuem preferências ideológicas e interesses comerciais, mas que também possuem normas profissionais, normas para produzir e validar a informação. Essas normas variam segundo a plataforma, ou seja, meios tradicionais têm formas distintas de verificar a informação dos veículos alternativos com suas bases na internet. Porém, também é certo, e creio que aqui está a chave, que os 
meios de comunicação, sobretudo os comerciais, apresentam informações sobre os governos de maneira estratégica.

Quando a opinião pública é favorável ao governo, por exemplo, ou quando a economia está funcionando muito bem e o presidente é popular, os veículos de comunicação comerciais, em geral, têm poucos incentivos para atacar o governo, porque os próprios leitores e as audiências não querem ouvir notícias ruins. Mas, se a economia piora e o governo começa a cair em popularidade, os meios começam a ter mais incentivos para publicar notícias negativas, porque a audiência está raivosa e é isso que quer escutar. Neste sentido, a produção de escândalo não é totalmente independente da popularidade do governo, principalmente com questões econômicas.

No livro (Pérez-Liñan, 2007), o senhor diz que os veículos de comunicação atuam nos processos de impeachment com um comportamento estratégico, 0 que não revela necessariamente uma atuação oportunista. Que atitudes levam a esse caminho? O que ainda é necessário estudar na atuação do jornalismo como um agente moral na cobertura sobre política?

Pessoalmente me interessaria que tivéssemos uma visão da imprensa mais como um ator institucional. Há toda uma linha de pesquisa que se preocupa com os impactos ou de que maneira as publicações da imprensa afetam a opinião pública. Esse é um tema muito importante. Porém, também me interessa pesquisar de que maneira a imprensa decide publicar certas informações. De que maneira obtém e em que condições decide publicar a informação e dar cobertura a um determinado tema. Acredito que isso não é estudar a imprensa somente como instituição, mas também os atores internos com objetivos de carreira, em particular os jornalistas e editores que negociam com os atores políticos as informações que recebem e combinam o que será publicado. Algo que é parte do processo jornalístico de todos os dias. Os jornalistas entendem essas rotinas, porém acredito que a ciência política não tem teorizado mais claramente como esse processo funciona. 
E no processo de impeachment, a imprensa se torna uma instituição fundamental na cobertura dos acontecimentos?

Sim, claro, o impeachment requer um crime de responsabilidade que precisa ser suficientemente crível para a opinião pública no acompanhamento do Congresso durante o processo. Para que a população acredite na existência deste crime e seja convencida de que ele existe, os meios precisam expor o delito para a opinião pública, tem que ocorrer escândalos que reforcem a acusação. Por esse motivo, a imprensa sempre, ou quase sempre, joga em uma posição chave nos processos de impeachment.

Se os escândalos se tornam uma arma política na cobertura da mídia durante $o$ processo de impeachment, há a utilização dos sistemas midiáticos para satisfazer o interesse de determinados agentes?

Os políticos entendem isso muito bem. Sempre entenderam. Vamos supor que os jornalistas são puramente profissionais e simplesmente buscam premissas. Ou mesmo, supor que os jornalistas nas redações busquem somente pensar em suas carreiras. Não vamos esquecer que os meios de comunicação, por sua vez, possuem objetivos a longo prazo e linhas editoriais. Uma premissa, ou um furo, significa que alguém passe uma informação confidencial e o motivo pelo qual este alguém entrega a informação do governo é porque quer afetar um adversário. Então, as premissas, quase sempre, surgem de fontes internas ao governo como parte de um conflito político interno ou de fontes da oposição que por algum motivo encontraram informações sobre a corrupção na administração adversária.

No caso do Brasil há um elemento adicional que é a capacidade investigativa do Poder Judiciário, algo inexistente em muitos países da América Latina. Isso é um elemento de imprevisibilidade para além dos meios de comunicação, porque há uma fonte adicional sobre a corrupção. O Poder Judiciário, por outro lado, tende a ser menos estratégico no uso da informação do que as fontes internas do governo, porque geram investigações como parte de um processo legal, relativamente público. Porém, está claro que o Poder Judiciário também filtra informações para a imprensa com fins políticos. $O$ caso do juiz 
Sérgio Moro foi muito claro. A divulgação da ligação interceptada entre Dilma e Lula foi um cálculo estratégico para impedir que Lula se tornasse ministro e que as investigações saíssem das mãos do juiz. Então, é possível dizer que todos os atores, inclusive o setor judicial, utilizam os filtros da imprensa como estratégia política.

\section{E a "judicialização" não torna o Legislativo e o Executivo dependentes dessa} esfera em suas decisões políticas, principalmente, no caso do impeachment ou até mesmo de decisões recentes que o Supremo tem tomado no caso brasileiro?

Em países como o Brasil, com um Poder Judiciário forte, esta esfera tem uma presença central durante o processo de impeachment. Cumpre um papel de autonomia e até mesmo em decidir quem fica ou sai de um poder, como vimos no caso de Renan Calheiros ${ }^{1}$. Porém, em boa parte dos países latino-americanos, a Justiça é muito fraca para cumprir o papel de decidir questões como essa. Portanto, as disputas são entre os presidentes e os Congressos ou, então, contra movimentos sociais.

O senhor acredita que os casos estudados nos anos de 1990 podem oferecer bases para entender as crises vivenciadas por Fernando Lugo, em 2012, e Dilma Rousseff, em 2016? Dado que nestes últimos momentos, os movimentos de esquerda ligados a sindicatos, organizações estudantis e ao Partido dos Trabalhadores foram para as ruas pedir a permanência dos presidentes no poder.

Os casos que estudei no livro (Pérez-Liñan, 2007), estruturalmente, se parecem muito com o que estamos vivendo hoje em dia porque os elementos que possibilitaram a queda

\footnotetext{
${ }^{1}$ Após o afastamento da presidência do Senado em decisão do ministro do Supremo Tribunal Federal Marco Aurélio Mello, no dia 5 de dezembro de 2016, Renan Calheiros não cumpriu a medida e foi absolvido por sete votos a três na corte no dia 7 de dezembro. A determinação do afastamento tinha o argumento de que um réu não poderia assumir um cargo na linha sucessória da presidência. A decisão do colegiado de ministros deferiu a permanência de Calheiros à frente do Senado, mas não na linha de sucessão presidencial. Decisão do STF disponível em: $<$ http://www.stf.jus.br/portal/processo/verProcessoTexto.asp?id=4210802\&tipoApp=RTF $>$. Acesso em: dezembro de 2016.
} 
dos presidentes foram muito similares: mobilizações sociais contra os presidentes, ruptura do escudo legislativo, condições econômicas debilitando as políticas dos presidentes e meios de comunicação expondo escândalos. Esses fatores que operavam nos anos 1990 voltaram a debilitar os presidentes na atualidade. A grande diferença, creio eu, e que tem a ver com essa questão do respaldo social também, é que os presidentes que sofriam impeachments nos anos 1990 eram neoliberais e, portanto, era muito fácil para nós criarmos uma narrativa para esses casos, porque poderíamos dizer que esses presidentes utilizaram políticas muito impopulares, então houve mobilizações contra isso e o Congresso reagiu à razão popular e começou um juízo político contra o presidente. É uma narrativa linear.

No contexto atual, essa narrativa é muito mais complexa e difícil de articular. Ambos são presidentes de esquerda. Então, o que estamos descobrindo é que num contexto de crise econômica e insatisfação social, as mobilizações sociais podem afetar qualquer presidente, não somente os neoliberais. No caso de Dilma, há um setor da população que está disposto a se mobilizar e respaldar a presidenta até o último momento. Foi um setor pequeno, relativamente, mas, no caso de Collor, não havia ninguém disposto a defendêlo. Já o caso de Lugo é interessante porque não há uma mobilização de rua para respaldar o presidente, porém, tampouco há manifestações contra o presidente. Em 2012, houve, no Paraguai, apenas uma manobra parlamentar contra Lugo. No entanto, ele não tinha popularidade suficiente para formar um escudo popular. Ninguém foi às ruas para defendê-lo e o Congresso pôde avançar com sua manobra sem mobilizações contrárias ao que estavam fazendo.

E a formação do escudo legislativo da presidenta Dilma, como o senhor analisa o caso? Faltou também essa possibilidade de articular um escudo popular e parlamentar para barrar o impeachment?

É claro que, no caso de Dilma, houve uma parte da sociedade que se mobilizou em defesa do governo, porém, outra enorme parte já estava se mobilizando contra. As manifestações de março de 2016 e as pesquisas de popularidade indicavam uma situação 
majoritariamente oposta à presidenta. Então, o Congresso sente que tem a possibilidade de avançar contra o governo sem custos para sua imagem. E as eleições municipais deste ano [2016] mostraram ainda mais que não houve um custo político para quem defendeu o impeachment.

O estudo realizado sobre a instabilidade política dos presidentes Collor, Bucaram, Samper, Perez, Cubas Grau e Gonzalez Macchi marca a utilização do impeachment como uma arma institucional para solucionar conflitos. Isso não se revela uma estratégia de retirar do poder alguém que não segue os preceitos políticos que estão em evidência no país? Não revela uma atitude golpista? Como pensar a situação diante da narrativa do golpe?

Do ponto de vista político e da ciência política, o argumento para chamar esse impeachment de golpe tem sentido, porque o que se tenta mostrar é que o processo contra Dilma foi ilegítimo e comparável a um golpe. É compreensível que se utilize esse conceito. Porém, no ponto de vista da ciência política, é também um pouco perigoso, porque o que se quer dizer na realidade como um golpe é, para grande parte da população brasileira, algo legítimo e constitucional. Então, essa confusão conceitual joga para os dois lados e acredito que politicamente é um tema perigoso. Agora, academicamente, o que precisamos enxergar é um alargamento conceitual, como afirma Giovane Sartori (Sartori, 1970), ou seja, uma situação na qual tentamos aumentar a denotação de um conceito sem modificar sua conotação.

Para evitar a confusão conceitual na ciência política, acredito que se torna importante distinguir os processos que podemos denominar como golpes nos quais há um ato de força com ou sem o respaldo do Congresso para a remoção do presidente. Neste sentido, a destituição do presidente brasileiro Carlos Luz em 1955 foi um golpe [Após a morte do presidente Getúlio Vargas, o Congresso articulou, juntamente com os militares, um golpe para impedir a posse de Luz, então presidente da Câmara dos Deputados, após o afastamento de Café Filho por motivações políticas. Apto para assumir, Luz foi julgado incapaz de exercer a presidência no Congresso ao mesmo tempo em que o General Lott 
organizou um golpe para impedi-lo de assumir]. Foi um golpe com a interferência do Congresso motivada por uma decisão militar. Esse caso precisa ser distinguido do caso de Dilma, no qual o Congresso autonomamente decidiu remover a presidenta É claro que há também uma discussão posterior, que é se o Congresso utiliza legitimamente a instituição do impeachment.

Eu acredito que, no caso de Dilma, há argumentos para sustentar que o Congresso abusou de seu poder constitucional, porque buscou uma desculpa para iniciar o juízo político. Porém, em benefício das pesquisas, é conveniente distinguir analiticamente entre golpes de Estado nos quais há uma intervenção do poder militar e casos de impeachment em que os Congressos manipulam o poder constitucional que possuem para justificar o crime de responsabilidade. Se olharmos para os casos da América Latina nos anos 1990, em quase todos, os Congressos manipularam esse poder de uma ou outra maneira. O mais extremo é o caso de Abdalá Bucaram no Equador, em 1997, uma situação na qual o Congresso não tinha a maioria legislativa necessária para gerar um impeachment. Então, pela maioria simples, declarou-se o presidente louco, mentalmente incapaz de exercer a função. Há oito casos de impeachment, entre 1992 e 2016. Na maior parte, houve manipulações nos procedimentos, algo que precisa ser problematizado pela Ciência Política e pelo Direito.

Mesmo não sendo o foco direto do livro sobre o impeachment e instabilidade política, o senhor detalha em um dos capítulos da obra o desenvolvimento midiático ao longo da redemocratização. Após os anos 2000 e agora, em pleno 2016, uma outra dinâmica envolve as relações entre os aparatos midiáticos, as novas mídias e os sites de redes sociais. Como relacionar este ambiente com as situações de crise vivenciadas no presidencialismo que resultam em um impeachment?

Esse é um tema que merece muita pesquisa. Minha hipótese é que as redes sociais e as novas mídias possuem um efeito ambíguo nos processos de impeachment. Por um lado, podem multiplicar o efeito das investigações midiáticas e a capacidade de mobilização da 
sociedade. As redes sociais facilitam a coordenação das manifestações populares contra o presidente, algo que foi um dos grandes temas no Egito em 2012. Por outro lado, as redes sociais também dirigem a opinião pública a fontes de informação alternativas aos meios de comunicação tradicionais, o que foi visto na campanha eleitoral dos Estados Unidos. É cada vez mais fácil para os diferentes grupos partidários na sociedade buscar fontes de informação que confirmam e reforçam sua interpretação partidária do mundo, e descartar as informações de meios tradicionais que investigam casos de corrupção e oferecem fontes verossímeis.

É possível pensar em instituições sólidas em períodos de extrema polarização política na atualidade, principalmente como partes da cobertura midiática e das próprias crises do regime presidencialista?

Eu acredito que a polarização debilita as instituições, porque estas possuem a função de regular os conflitos. Num contexto assim, a opinião pública não crê na solução dos conflitos, mas sim numa solução única para um lado ou outro. Portanto, os líderes têm poucos incentivos para negociar e muitos para enfrentar e denunciar as instituições. Em alguns casos, essa estratégia funciona. Collor tentou algo parecido e não funcionou nesse contexto, porém, hoje em dia, para muitos líderes latino-americanos, a estratégia é denunciar as instituições. Isso funcionou para Rafael Correa no Equador, Uribe na Colômbia e, possivelmente, vai funcionar para Donald Trump nos Estados Unidos. Enfim, a polarização tende a impulsionar o papel dos líderes com discursos mais radicais e enfraquecer a capacidade das instituições em regular os conflitos.

Por fim, como o professor analisa a necessidade de repensar o sistema presidencialista nestes tempos de crise? Como questões econômicas, midiáticas, legislativas e populares se tornam importantes aos estudos sobre a instabilidade de governo e a estabilidade do regime? 
O grande tema pendente para o presidencialismo é determinar se o impeachment deveria evoluir ao equivalente ao voto de censura do parlamentarismo e, portanto, um procedimento essencialmente político. Ou então, se o impeachment deveria funcionar como um procedimento estritamente controlado e destinado a remover presidentes quando há provas muito claras de certos tipos de abuso de poder. Quaisquer destas soluções seriam funcionais aos sistemas presidenciais que podem operar com as duas propostas. O que cria uma grande instabilidade e uma crise de legitimidade da instituição do sistema presidencial é quando existem incertezas sobre o que o impeachment realmente representa. Enquanto a oposição reclama a possibilidade do impeachment como um voto de censura, quem está no governo reivindica um procedimento legal com um critério muito mais restrito. E, é claro, essas posições mudam dependendo de quem está dentro ou fora do governo, o que gera um debate sobre a natureza da instituição e sua legitimidade. Então, creio que parte dos debates nas escolas de Direito e Ciência Política deveria ser para onde o impeachment deve evoluir para se tornar uma instituição eficiente no sistema presidencial e qual é o consenso que deveríamos ter sobre o que essa instituição deve cumprir.

\section{Referências}

MAINWARING, Scott; PÉREZ-LIÑÁN, Aníbal. Democracies and dictatorships in Latin America: Emergence, Survival, and Fall. Cambridge. Cambridge University Press, 2013.

PEREZ-LIÑAN, Aníbal. Democracia, Radicalización, y Agencia Política en América Latina. Debates, 10, 2016.

SAAP, 2016. Juicio político, cultura legal y escudo popular. Argentina: Revista ¿Juicio político o golpe legislativo? Sobre las crisis constitucionales en los años noventa. Espanha: América Latina Hoy, 2000.

Presidential impeachment and the new political instability in Latin America. Cambridge University Press, 2007.

SARTORI, Giovanni. Concept misinformation in comparative politics. American Political Science Review, vol. 64, n 4, 1970. 


\section{O autor}

Luãn Chagas é jornalista e doutorando do Programa de Pós-Graduação em Comunicação da Universidade do Estado do Rio de Janeiro (PPGCOM-UERJ). luaanchagas@gmail.com 